\title{
Electrocatalytic Polysulfide Traps and their Conversion to long- chain Polysulfides using rGO-Pt composite as electrocatalyst to Improve the Performance of Li-S Battery
}

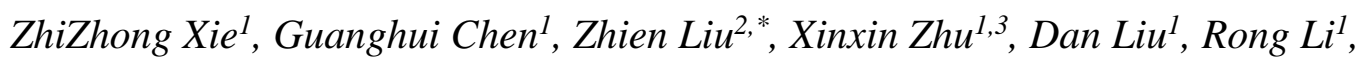 \\ Deyu $Q u^{1, *}$, Junsheng $\mathrm{Li}^{1}$ \\ ${ }^{1}$ Department of Chemistry, School of Chemistry, Chemical Engineering and Life Sciences, Wuhan \\ University of Technology, 122 Luoshi Road, Wuhan, 430070 Hubei, PR China \\ ${ }^{2}$ School of Automotive Engineering,Wuhan University of Technology, 122 Luoshi Road, Wuhan, \\ 430070 Hubei, PR China \\ ${ }^{3}$ State Key Laboratory of Advanced Technology for Material Synthesis and Processing, Wuhan \\ University of Technology, 122 Luoshi Road, Wuhan, 430070 Hubei, PR China \\ *E-mail: $\underline{\text { zen21@whut.edu.cn, deyuquwuhan@163.com }}$
}

doi: $10.20964 / 2019.12 .59$

Received: 24 June 2019 / Accepted: 28 September 2019 / Published: 29 October 2019

Serious shuttle effect and sluggish reaction kinetics are the two major barriers that limit the cathode cycling stability in lithium-sulfur batteries. In this study, we deviate from the prevalent approach compositing sulfur with various carbonaceous materials by introducing electrocatalysis concept in lithium-sulfur chemistries. Two-dimensional graphene has been used as model system to support electrocatalyst Pt. Uniform dispersion of Pt nanoparticles on graphene layers not only demonstrate to preferential adsorption of soluble polysulfide species, but also catalyze efficiently transformation to long-chain polysulfides in the subsequent redox process. The result rGO-Pt/S composite shows a $29.5 \%$ enhancement in capacity over pristine $\mathrm{rGO} / \mathrm{S}$ electrode. More impressively, $\mathrm{rGO}-\mathrm{Pt} / \mathrm{S}$ electrode exhibits good cycling stability at a high rate of $2 \mathrm{C}$ corresponding to a tiny capacity fading rate of $0.01 \%$ per cycle over 300 discharge/charge cycles. Thus, this work provides a facile strategy for improving the performance of $\mathrm{Li}-\mathrm{S}$ batteries toward practical application.

Keywords: Pt; bi-functional electrocatalyst; polusulfide; shuttle-effect

\section{$\underline{\text { FULL TEXT }}$}

(C) 2019 The Authors. Published by ESG (www.electrochemsci.org). This article is an open access article distributed under the terms and conditions of the Creative Commons Attribution license (http://creativecommons.org/licenses/by/4.0/). 